\title{
Arterial Stiffness and its Related Factors in Patients on Hemodialysis
}

\author{
Burkay Yakar $^{1}$, Mustafa Demir², Erhan Onalan³ and Mehmet Onur Kaya ${ }^{4}$ \\ ${ }^{1}$ Department of Family Medicine, Faculty of Medicine, Firat University, Turkey \\ ${ }^{2}$ Department of Nephrology, Faculty of Medicine, Firat University, Turkey \\ ${ }^{3}$ Department of Internal Medicine, Faculty of Medicine, Firat University, Turkey \\ ${ }^{4}$ Department of Biostatistics and Medical Informatics, Faculty of Medicine, Firat University, Turkey
}

\begin{abstract}
Objective: To evaluate the prevalence of arterial stiffness in patients on hemodialysis and related factors that aggravate the condition.

Study Design: Prospective-cohort study.

Place and Duration of Study: Department of Nephrology, Firat University Hospital, Turkey, from August to October 2019.

Methodology: Central blood pressure (BP), augmentation index (Alx) and aortic pulse wave velocity score (PWVs) were assessed using the mobil-o-graph pulse wave velocity system. Increased arterial stiffness (AS) wgnas defined by the aortic PWV of $>10 \mathrm{~m} / \mathrm{s}$.

Results: The mean PVWs were $8.14 \pm 2.39 \mathrm{~m} / \mathrm{s}$ the mean Alx was $21.23 \pm 11.58 \mathrm{~m} / \mathrm{s}$, and AS was $33.7 \%$ in hemodialysis patients. Systolic blood pressure, pulse rate, pulse pressure, central systolic blood pressure, older age, HD vintage, HT vintage, creatinine, CRP and neutrophil leukocyte ratio (NLR), were related factors with AS. Multivariate linear regression analysis showed that systolic blood pressure $(\beta=0.322 ; 95 \% \mathrm{Cl}$ : $0.007-0.042 ; p=0.006)$, and age of patients $(\beta=0.787 ; 95 \% \mathrm{Cl}$ : $0.095-0.127 ; p<0.001$ ) were independent determinants of PWVs.

Conclusion: The frequency of AS was $33.7 \%$ in hemodialysis patients without a history of cardiovascular disease. Increased age and systolic blood pressure were independent factors affecting PWV. Effective blood pressure control therapy can reduce AS in hemodialysis patients.
\end{abstract}

Key Words: Pulse wave velocity, Arterial stiffness, Cardiovasculer disease, Systolic blood pressure, Hemodialysis.

How to cite this article: Yakar B, Demir M, Onalan E, Kaya MO. Arterial Stiffness and its Related Factors in Patients on Hemodialysis. J Coll Physicians Surg Pak 2021; 31(02):138-143.

\section{INTRODUCTION}

Chronic kidney disease (CKD) is an important health problem today due to its high incidence and prevalence. Chronic renal failure is defined as a chronic and progressive metabolic-endocrine dysfunction that develops as a result of a decrease in glomerular filtration value and failure to adjust the fluid-solute balance of the kidney. The prevalence of chronic kidney disease is estimated to be between $8 \%$ and $16 \%$ worldwide. ${ }^{1}$

Cardiovascular morbidity and mortality increase in end-stage renal disease (ESRD). ESRD is associated with increased mortality compared to the normal population, and more than half of deaths are due to cardiovascular disease (CVD). In ESRD patients, CVD increases 10-30-fold compared to the normal population. ${ }^{2}$

Correspondence to: Dr. Burkay Yakar, Department of Family Medicine, Faculty of Medicine, Firat University, Turkey

E-mail: byakar@firat.edu.tr

Received: November 20, 2020; Revised: January 14, 2021; Accepted: February 08, 2021

DOI: https://doi.org/10.29271/jcpsp.2021.02.138
Itisimportant to treatmajorriskfactors (diabetes mellitus, hypertension and dislipidemia) as well as non-traditional risk factors in order to reduce CVD mortality in patients with CKD. Endothelial dysfunction, vascularcalcification and AS are non-traditional risk factors, closely associated with CVD. Arterio sclerosis is closely related to AS. As a result of atherosclerosis, it causes important clinical outcomes such as increased stiffness of the large arteries, increased systolic blood pressure and pulse pressure, left ventricular hypertrophy, and decreased coronary perfusion. ${ }^{3}$ Today, AS, which is a marker of arterial disease, can be measured with PWV, which is a non-invasive technique. Large artery stiffness can be evaluated with PWV method. The previous studies have shown that there is a relationship between PWV score (PVWs) and high cardiovascular risk.

It has been reported that AS and arterial calcification increase, so it may contribute to the development of CVD. ${ }^{4}$ The current study aimed to investigate the prevalence of $A S$ and the factors related with AS in ESRD patients, treated with hemodialysis.

\section{METHODOLOGY}

This cross-sectional study was conducted in the Hemodialysis Unit of tertiary university hospital from August to October 2019. 
A total of 86 patients, with undergoing hemodialysis for ESRD, were included in the study. Patients, aged over 18 years, registered in the hemodialysis unit, having end-stage renal failure for at least one year, and undergoing hemodialysis treatment three times a week, were included in the study. Patients with instable hemodynamic parameters, chronic atrial fibrillation, severe aortic stenosis, peripheral artery disease, recent myocardial infarction, and cerebrovascular event within last three months, decompensated heart failure, acute infection, morbid obesity, and bilateral arteriovenous (AV) fistula, were excluded from the study.

The socio-demographic characteristics of the participants were obtained with the questionnaire form prepared by scanning the literature data. Their demographic characteristics, included age, gender, marital status, educational level, comorbid diseases (hypertension and diabetes mellitus), smoking habits, duration of HT and hemodialysis. The heights of the patients were measured with a standing and $0.1 \mathrm{~cm}$ sensitive accurate wall mounted height meter. The dry weight of the patients were measured with sensitive digital scale. Body mass index (BMI) was calculated using the conventional Queteletformula $\left(\mathrm{kg} / \mathrm{m}^{2}\right)$.

Blood samples were drawn in the fasting condition from all patients. All blood samples were collected before the hemodialysis period. Hemogram, blood urea nitrogen (BUN), creatinine $(\mathrm{Cr})$, parathyroid hormone (PTH), lipid profile, C-reactive protein (CRP), Calcium (Ca) and Phosphate (P) levels were evaluated in blood samples. The neutrophil-lymphocyte ratio was calculated by dividing the neutrophil counts of all patients by lymphocyte counts.

For determination of central BP, PWV and augmentation index (Alx), the mobil-o-graph (Stolberg, Germany) was used. It is noninvasive gold standard commercially available brachial-cuffbased oscillometric device for the assessment of central vascular pressures and aortic PWV score. Its BP detection unit has been validated in accordance with the European Society of Hypertension international protocols. Simultaneous brachial BP, PWV, and Alx measurements are provided by the oscillometric mobil-o-graph arteriograph device. The derived PWV is an indirect estimate of large-artery stiffness based on mathematical models incorporating several parameters derived from pulse wave analysis and wave-separation analysis as previously published. ${ }^{5}$ The first valid oscillometric measurement was used in the analysis. Brachial artery systolic and diastolic BP were measured at the non-AV fistula arm of HD patients using a validated aneroid sphygmomanometer to compare mobil-o-device's systolic and diastolic blood pressure measurements. Pulse rate was measured simultaneously with AS measurements. Pulse pressure was estimated as the difference between systolic and diastolic blood pressures. Before starting the measurements, the patients were informed about the mobil-o-graph device and the measurement. The patients were asked not to move or speak during the measurement. All measurements were performed before hemodialysis, in a quiet room at a stable temperature $\left(20 \pm 2^{\circ} \mathrm{C}\right)$, and after resting the patients in supine position for at least 10 minutes. All measurements were made from the non-fistula arms of the patients. The arm circumference of the participants was measured and size appropriate cuff was determined. Increased AS was defined by the aortic PWV of $>10$ $\mathrm{m} / \mathrm{s}$ proposed in the $2018 \mathrm{ESC}$ Guidelines. According to the guideline, PWV scores above the threshold are associated with increased cardiovascular risk. ${ }^{6}$

Statistical analysis of the datas was performed by IBM SPSS 22 statistics package programme. The distribution of continuous data was analysed using the Shapiro-Wilk test. Descriptive data are given as mean \pm SD for continuous variables with normal distribution, median (quartile 1-quartile 3) for continuous data with non-normal distribution, and number (n) and percentage (\%) for categorical variables. For comparison of two independent groups, Student-ttest was used fornormal distributed continuous data, Mann-Whitney U-test for non-normal distributed continuous data. Pearson Chi-square test was used to analyse categorical data, in relation between of two continuous data. Considering the distribution of continuous data, Pearsoncorrelation analysis or Spearman correlation analysis was used to examine the relationship between continuous variables. Multivariate linear regression analyses were performed to determine predictors of arterial stiffness parameters. A value of $p<0.05$ was considered statistically significant.

\section{RESULTS}

A total of 86 hemodialysis patients were included in the study. The mean age was $53.80 \pm 16.98$ years; and $66.3 \%(n=57)$ of the participants were males. In the study cohort $62.8 \%(n=54)$ had hypertension and $29.1 \%(n=25)$ had diabetes mellitus; $16.3 \%(n=14)$ of patients declared smoking. The mean PWV score of the patients were $8.14 \pm 2.39 \mathrm{~m} / \mathrm{s}$ and the mean Alx score was $21.23 \pm 11.58 \mathrm{~m} / \mathrm{s}$. The rate of patients with AS (PWV $>10 \mathrm{~m} / \mathrm{s})$ were $33.7 \%(n=29)$. The age was significantly higher in the AS group $(p<0.001)$. Arterial stiffness was significantly higher in married $(p=0.001)$, hypertensive $(p=0.024)$ and diabetic patients $(p=0.022)$. The relationship between AS and socio-demographic characteristics of the participants is presented in Table I.

Systolic blood pressure $(p=0.006)$, pulse pressure $(p<0.001)$, creatinine $(p<0.001)$, ferritin $(p=0.029)$, and HT vintage $(p=0.011)$ were significantly higher in AS. Comparison of AS with blood pressure and biochemical parameters of patients is shown in Tablell.

Bivariatecorrelationanalysis demonstrateda significantassociation between PWV and patient age, systolc blood pressure, pulse, pulse pressure, central systolic BP, HD vintage, HT vintage, creatinine, Crp and NLR (Table III).

Multivariate linear regression analysis showed that systolic blood pressure $(\beta=0.322 ; 95 \% \mathrm{Cl}: 0.007-0.042 ; p=0.006)$ and age of patients ( $\beta=0.787 ; 95 \% \mathrm{Cl}: 0.095-0.127 ; p<0.001)$ were independent determinants of PWV (Table IV). 


\begin{tabular}{|c|c|c|c|c|}
\hline Characteristics & $\begin{array}{l}\text { PWV } \leq 10(\mathrm{~m} / \mathrm{s}) \\
\mathrm{n}(\%)\end{array}$ & $\begin{array}{l}\text { PWV >10 (m/s) } \\
\text { n (\%) }\end{array}$ & $\begin{array}{l}\text { Total }(n=86) \\
n(\%)\end{array}$ & p-value \\
\hline Age (year) & $46.23 \pm 14.44$ & $68.69 \pm 10.59$ & $53.80 \pm 16.98$ & $<0.001$ \\
\hline \multicolumn{5}{|l|}{ Gender } \\
\hline Female & $18(31.6)$ & $11(37.9)$ & $29(33.7)$ & 0.556 \\
\hline Male & $39(68.4)$ & $18(62.1)$ & $57(66.3)$ & \\
\hline \multicolumn{5}{|l|}{ Marital status } \\
\hline Single & $23(40.4)$ & $2(6.9)$ & $25(29.1)$ & 0.001 \\
\hline Married & $34(59.6)$ & $27(93.1)$ & $61(70.9)$ & \\
\hline \multicolumn{5}{|l|}{ Educational status } \\
\hline Below high school & $36(63.2)$ & $24(82.8)$ & $60(69.8)$ & 0.061 \\
\hline High school and above & $21(36.8)$ & $5(17.2)$ & $26(30.2)$ & \\
\hline \multicolumn{5}{|l|}{ Income perception } \\
\hline Insufficient & $28(49.1)$ & $13(44.8)$ & $41(47.7)$ & 0.706 \\
\hline Sufficient & $29(50.9)$ & $16(55.2)$ & $45(52.3)$ & \\
\hline \multicolumn{5}{|l|}{ Hypertension diseas } \\
\hline Have not & $26(45.6)$ & $6(20.7)$ & $32(37.2)$ & 0.024 \\
\hline Have & $31(54.4)$ & $23(79.3)$ & $54(62.8)$ & \\
\hline \multicolumn{5}{|c|}{ Hypertension drug use status } \\
\hline Does not use & $35(61.4)$ & $17(58.6)$ & $52(60.5)$ & 0.803 \\
\hline Use & $22(38.6)$ & $12(41.4)$ & $34(39.5)$ & \\
\hline \multicolumn{5}{|l|}{ Diabetes mellitus diseas } \\
\hline Have not & $45(78.9)$ & $16(55.2)$ & $61(70.9)$ & 0.022 \\
\hline Have & $12(21.1)$ & $13(44.8)$ & $25(29.1)$ & \\
\hline \multicolumn{5}{|l|}{ Tobacco use } \\
\hline Does not use & $45(78.9)$ & $27(93.1)$ & $72(83.7)$ & 0.093 \\
\hline Use & $12(21.1)$ & $2(6.9)$ & $14(16.3)$ & \\
\hline \multicolumn{5}{|c|}{ Aortic pulse wave velocity (PWV) and augmentation index (Alx) scores } \\
\hline PWV $(\mathrm{m} / \mathrm{s})[$ mean $\pm \mathrm{sd}]$ & $8.14 \pm 2.39$ & & & \\
\hline Alx (\%) $[$ mean \pm sd] & $21.23 \pm 11.58$ & & & \\
\hline \multicolumn{2}{|c|}{$\mathrm{PWV}(\mathrm{m} / \mathrm{s})$} & \multicolumn{3}{|l|}{$\mathrm{n} \quad(\%)$} \\
\hline \multicolumn{2}{|c|}{ No arterial stiffness (PWV $\leq 10 \mathrm{~m} / \mathrm{s}$ ) } & \multicolumn{3}{|l|}{$57(66.3)$} \\
\hline \multicolumn{2}{|c|}{ Arterial stiffness (PWV >10 m/s) } & \multicolumn{3}{|l|}{$29(33.7)$} \\
\hline \multicolumn{2}{|c|}{ Total } & \multicolumn{3}{|l|}{$86 \quad(100.0)$} \\
\hline
\end{tabular}

\begin{tabular}{|c|c|c|c|}
\hline Variables & No arterial stiffness $(n=57)$ & Arterial stiffness $(n=29)$ & p-value \\
\hline BMI $\left(\mathrm{kg} / \mathrm{m}^{2}\right)$ & $23.54 \pm 4.94$ & $24.94 \pm 5.83$ & 0.248 \\
\hline \multicolumn{4}{|l|}{ Brachial BP } \\
\hline Systolic BP (mmHg) & $117.51 \pm 28.48$ & $140.76 \pm 37.81$ & 0.006 \\
\hline Diastolic BP (mmHg) & $78.56 \pm 16.91$ & $77.45 \pm 18.61$ & 0.781 \\
\hline Pulse Pressure $(\mathrm{mmHg})$ & $40.42 \pm 13.38$ & $63.31 \pm 24.87$ & $<0.001$ \\
\hline \multicolumn{4}{|l|}{ Central BP } \\
\hline Systolic BP (mmHg) & $121.89 \pm 19.08$ & $133.45 \pm 28.07$ & 0.027 \\
\hline Diastolic BP (mmHg) & $78.89 \pm 14.38$ & $80.00 \pm 16.34$ & 0.748 \\
\hline BUN (mg/dl) & $147.02 \pm 43.57$ & $141.64 \pm 34.10$ & 0.571 \\
\hline Creatinine (mg/dl) & $8.96 \pm 2.97$ & $7.24 \pm 1.28$ & $<0.001$ \\
\hline Calcium (mg/dl) & $8.64 \pm 0.84$ & $8.70 \pm 0.88$ & 0.742 \\
\hline Phosphate (mg/dl) & $5.22 \pm 1.36$ & $4.78 \pm 1.21$ & 0.147 \\
\hline PTH $(p g / m l)$ & $434.00(260.90-617.00)$ & $363.70(165.95-603.15)$ & 0.313 \\
\hline T. Cholesterol (mg/dl) & $163.15 \pm 42.71$ & $172.22 \pm 35.38$ & 0.343 \\
\hline Triglycerides (mg/dl) & $173.87 \pm 80.57$ & $199.33 \pm 116.80$ & 0.314 \\
\hline $\mathrm{HDL}(\mathrm{mg} / \mathrm{dl})$ & $33.00(26.00-41.40)$ & $31.90(25.70-41.10)$ & 0.828 \\
\hline $\mathrm{LDL}(\mathrm{mg} / \mathrm{dl})$ & $88.43 \pm 35.32$ & $98.41 \pm 30.43$ & 0.213 \\
\hline Ürik asit (mg/dl) & $6.20 \pm 1.36$ & $5.88 \pm 1.01$ & 0.287 \\
\hline $\mathrm{Ca} \times \mathrm{PO}_{4}$ & $45.18 \pm 12.23$ & $41.47 \pm 11.50$ & 0.187 \\
\hline NLR & $2.95 \pm 1.19$ & $3.48 \pm 1.24$ & 0.059 \\
\hline $\mathrm{Crp}(\mathrm{mg} / \mathrm{dl})$ & $5.30(3.13-12.10)$ & $8.58(3.33-18.28)$ & 0.115 \\
\hline Ferritin $(\mu \mathrm{g} / \mathrm{L})$ & $423.00(239.00-1010.00)$ & 679.00 (434.78-1142.98) & 0.029 \\
\hline HD vintage (year) & $5.00(2.00-7.50)$ & $4.00(1.00-6.00)$ & 0.115 \\
\hline HT vintage (year) & $4.00(0.00-12.50)$ & $10.00(4.50-20.00)$ & 0.011 \\
\hline
\end{tabular}

Table III: Correlation between PWV score and continuous variables.

\begin{tabular}{|l|l|l|l|l|l|}
\hline \multirow{2}{*}{ Variables } & PVW & \multirow{2}{*}{ Variables } & PWV & r & p \\
\cline { 2 - 5 } & $\mathbf{r}$ & $\mathbf{p}$ & T. Cholestrole & 0.091 \\
\hline Systolic BP & 0.432 & $<0.001$ & HDL & 0.417 \\
\hline Diastolic BP & 0.077 & 0.480 & 0.129 & 0.247 \\
\hline
\end{tabular}




\begin{tabular}{|c|c|c|c|c|c|}
\hline Pulse/min & -0.278 & 0.009 & LDL & 0.130 & 0.245 \\
\hline Pulse Pressure & 0.575 & $<0.001$ & Triglycerids & 0.004 & 0.971 \\
\hline AIX & 0.021 & 0.849 & Calcium & 0.041 & 0.713 \\
\hline Central SBP & 0.339 & 0.001 & Phosphate & -0.110 & 0.322 \\
\hline Central DBP & 0.105 & 0.337 & PTH & -0.092 & 0.407 \\
\hline Age & 0.800 & $<0.001$ & Ferritin & 0.170 & 0.124 \\
\hline HD vintage (year) & -0.248 & 0.021 & Crp & 0.277 & 0.011 \\
\hline HT vintage (year) & 0.319 & 0.003 & BMI & 0.181 & 0.095 \\
\hline BUN & -0.082 & 0.459 & $\mathrm{Ca} * \mathrm{PO}_{4}$ & -0.092 & 0.406 \\
\hline Creatinine & -0.401 & $<0.001$ & NLR & 0.300 & 0.006 \\
\hline Uric acid & -0.162 & 0.145 & & & \\
\hline
\end{tabular}

Table IV: Multivariate linear regression analysis to determine independent predictors of PWV.

\begin{tabular}{|c|c|c|c|}
\hline \multirow{2}{*}{ Variables } & \multicolumn{3}{|c|}{$\operatorname{PWV}(\mathrm{m} / \mathrm{s}) \quad R^{2}=0.856, \mathrm{p}<0.001$} \\
\hline & Coefficient & $95 \% \mathrm{Cl}$ & p-value \\
\hline Systolic BP & 0.322 & $0.007-0.042$ & 0.006 \\
\hline Pulse & 0.092 & $-0.001-0.033$ & 0.064 \\
\hline Pulse pressure & 0.092 & $-0.013-0.033$ & 0.369 \\
\hline Central SBP & 0.050 & $-0.008-0.019$ & 0.454 \\
\hline Age & 0.787 & $0.095-0.127$ & $<0.001$ \\
\hline HD vintage (year) & -0.008 & $-0.052-0.044$ & 0.867 \\
\hline HT vintage (year) & 0.094 & $-0.001-0.056$ & 0.057 \\
\hline Creatinine & -0.026 & $-0.117-0.070$ & 0.621 \\
\hline Crp & 0.087 & $0.000-0.009$ & 0.069 \\
\hline NLR & -0.001 & $-0.196-0.190$ & 0.977 \\
\hline
\end{tabular}

\section{DISCUSSION}

The current study was found the mean PWV score of $8.14 \pm$ $2.39 \mathrm{~m} / \mathrm{s}$. AS prevalence was found $33.7 \%$ in study population. In three different studies previously reported, the mean PWC scores was $10.5,9.4$ and 8.80 , respectively. ${ }^{7-9}$ The mean PWV score obtained in the current study was similar to the literature data; which suggested that the study measurements were reliable. According to current study, $33.7 \%$ of hemodialysis patients had AS. Thanakitcharu et al. reported the prevalence of AS in $59 \%$ of patients with chronic renal failure, ${ }^{10}$ and Utescu et al. reported prevalence of AS in $43 \%$ among hemodialysis patients. ${ }^{9}$ The prevalence of AS in current study was found to be lower than previous studies among hemodialysis patients. Patients with known cardiovascular disease were excluded from current study, so AS prevalance may be lower than literature data.

The most of previous studies reported that there was a positive relation between AS and all-cause or cardiovascular mortality. ${ }^{11-15}$ Therefore, it is important to determine the factors affecting AS. Several estimated associated factors of AS were confirmed by the present study. Some factors found to be significantly associated with AS included aging, diabetes mellitus, hypertension, pulse pressure, serum creatinine, ferritin and duration of hypertension. In similar studies among hemodialysis patients, factors affecting AS support this study findings. ${ }^{9,10}$ Age, diabetes mellitus, hypertension, and the duration of hypertension are data expected to affect vascular stiffness. In clinical practice, these factors are reported as non-modifiable risk factors in the European Guidelines on cardiovascular disease prevention. ${ }^{15}$ The current study data showed that high serum creatinine, ferritin and pulse pressure were associated with AS. These factors are important because these are modifiable factors, which can reduce AS by fight against these factors. Ha et al. reported that ferritin levels were independently corraleted with AS. ${ }^{16}$ Lin et al. reported that serum ferritin associated with the progressive AS, especially when serum ferritin $>500$ $\mathrm{ng} / \mathrm{mL}$ in hemodialysis patients. ${ }^{17}$ The current study results showed that ferritin level is important in reducing AS. In patients with hemodialysis, especially keeping ferritin levels below $500 \mathrm{ng} / \mathrm{dl}$ may contribute to reducing AS. A recent study, which was conducted with 1,290 untreated patients by Mourad et al., showed that plasma creatinine level is associated with arterial stiffness. ${ }^{18}$ Kharlamova et al. reported that creatinine levels were independently corraleted with arterial stiffness. ${ }^{19}$ The data obtained in this study were similar with the literature. In this context, the present researchers could reduce AS by controlling serum creatinine with effective hemodialysis programmes.

The predictivity of the PVW score for cardiovascular events had evaluated in a meta-analysis study by Ben-Shlomo et al. As a result of that study, it was reported that the PVW score could be useful in better determining the population with high risk of cardiovascular disease and in the management of aggressive risk factors. ${ }^{20}$ In another study, Vlachopoulos et al. reported that the high PWV score is an important determinant of cardiovascular events and deaths from all causes. An increase in aortic PWV score of $1 \mathrm{~m} / \mathrm{s}$ or of one SD has been associated with a $10 \%$ to $40 \%$ increase in the risk of cardiovascular events and all-cause death. ${ }^{3}$ In this study, systolic blood pressure, pulse rate, pulse pressure, central systolic blood pressure, age, duration of hemodialysis, duration of HT, creatinine, CRP and NLR found to be associated with PWV. In multivariate linear regression analysis model, age and systolic blood pressure were significantly related 
with PWV independent of other factors. In many studies, age has been reported as a risk factor for AS and high PWV score. ${ }^{8-10}$ Age is also a non-modifiable risk factor for cardiovascular disease. ${ }^{15}$ The effect of age factor on PVW and arterial stiffness was an expected finding.

The most important finding obtained in this study is the determination of high blood pressure as an independent factor on PWV and AS. In many studies, the relationship between high blood pressure and AS was similar to this data. ${ }^{7,9,10,21}$ High blood pressure is a modifiable risk factor for AS. Laurent et al. reported that AS was an independent risk factor for cardiovascular mortality. ${ }^{11}$ This data suggests that AS, risks of cardiovascular disease and cardiovasculer mortality may be reduced by effective blood pressure control. Other modifiable risk factors affecting PWV score in this study were pulse pressure, pulse rate, central systolic pressure, creatinine, CRP and NLR. In the literature, creatinine, pulse pressure, central systolic blood pressure and heart rate were reported to be associated with PWV.,10,22 It has been reported in many studies that the increase in neutrophil-leukocyte ratio associated with systemic inflammation is positively correlated with the increase in the PWV score. ${ }^{23,24}$ Similar to the literature, NLR and CRP, which is an indicator of inflammation, were associated with PWV score in this study. The findings of this study were supported by literature data. In future studies, it may be focused on modifiable factors affecting AS and PWV, because the patients can be protected from cardiovascular morbidity and mortality by reducing modifiable risk factors.

There are several potential limitations of our study. First, because of the cross-sectional design of this study, the data do not directly indicate a cause-effect relationship. The small number of patients may be insufficient to determine the factors affecting AS and PWV score. Another limitation of the study was that some data (duration of HT and DM, duration of hemodialysis, smoking, etc.) were obtained, based on patient declaration.

\section{CONCLUSION}

The prevalence of AS in hemodialysis patients was $33.7 \%$ in this study. Systolic blood pressure, pulse rate, pulse pressure, central systolic blood pressure, age, duration of hemodialysis, duration of HT, creatinine, CRP and NLR found to be associated with PWV. PWV-related factors except age, HT duration, and HD duration were found to be modifiable factors. Age and blood pressure were found to be related to PWV, independent of other factors. The data of this study once again highlighted the importance of preventing modifiable risk factors in reducing cardiovascular mortality and morbidity.

\section{CONFLICT OF INTEREST:}

The authors declared no conflict of interest.

\section{ETHICAL APPROVAL:}

The study protocol was approved by the Ethics Committee of Firat University (Number:15-17, Date: 17/10/2019).

\section{PATIENTS' CONSENT:}

Written informed consents were obtained from all patients. The study was conducted in accordance with the principles of the Declaration of Helsinki.

\section{AUTHORS' CONTRIBUTION:}

BY: Data collection, design, compiling, and discussion, conceived the project, and authored the manuscript.

MD: Contributed to collecting and analysing data, and discussion.

EO: Contributed to collecting data and discussion.

MOK: Contributed to collecting data, statistics and analysing data.

\section{REFERENCES}

1. Lv JC, Zhang LX. Prevalence and disease burden of chronic kidney disease. Adv Exp Med Biol 2019; 1165:3-15. http://doi.org/10.1007/978-981-13-8871-2_1.

2. Provenzano M, Coppolino G, Faga T, Garofalo C, Serra R, Andreucci M. Epidemiology of cardiovascular risk in chronic kidney disease patients: The real silent killer. Rev Cardiovasc Med 2019; 20(4):209-20. http://doi.org/10.31083/j.rcm.2019.04.548

3. Georgianos PI, Sarafidis PA, Lasaridis AN. Arterial stiffness: A novel cardiovascular risk factor in kidney disease patients. Curr Vasc Pharmacol 2015; 13(2):229-38. doi.org/ 10.2174/15701611113119990147.

4. Ohkuma T, Ninomiya T, Tomiyama H, Kario K, Hoshide S, Kita $Y$, et al. Collaborative group for J-BAVEL (japan brachialankle pulse wave velocity Individual participant data meta-analysis of prospective studies)*. Brachial-ankle pulse wave velocity and the risk prediction of cardiovascular disease: An Individual participant data meta-analysis. hypertension 2017 ; 69 ( 6 ) : $1045-52$. http://doi.org/10.1161/hypertensionaha.117.09097.

5. Wassertheurer S, Kropf J, Weber T, van der Giet M, Baulmann J, Ammer M, et al. A new oscillometric method for pulse wave analysis: Comparison with a common tonometric method. J Hum Hypertens 2010; 24(8):498-504. http://doi.org/10.1038/jhh.2010.27.

6. Williams B, Mancia G, Spiering W, Agabiti Rosei E, Azizi M, Burnier M, et al. ESC Scientific Document Group. 2018 $\mathrm{ESC} / \mathrm{ESH}$ Guidelines for the management of arterial hypertension. Eur Heart J 2018; 39(33):3021-3104. http://doi.org/10.1093/eurheartj/ehy339.

7. Liu W, Zhou J, Chen J, Meng M, Li X, Gao C, et al. Ambulatory arterial stiffness index and its role in assessing arterial stiffness in dialysis patients. J Hypertens 2017; 35(6): 1297-1301. http://doi.org/10.1097/hjh.0000000000001309.

8. Georgianos PI, Mpoutsiouki F, Sabani E, Stamatiadis DN, Liakopoulos V, Balaskas EV, et al. Hemodialysis patients with intradialytic rise in blood pressure display higher baseline aortic stiffness and negligible drop in augmentation index with dialysis. Int Urol Nephrol 2016; 48(4):601-8. 
http://doi.org/10.1007/s11255-015-1205-8.

9. Utescu MS, Couture V, Mac-Way F, De Serres SA, Marquis $\mathrm{K}$, Larivière $\mathrm{R}$, et al. Determinants of progression of aortic stiffness in hemodialysis patients: A prospective longitudinal study. Hypertension 2013; 62(1):154-60. doi.org/10. 1161/hypertensionaha.113.01200

10. Thanakitcharu $P$, Jitsuparat $Y$, Jirajan B. Prevalence of arterial stiffness and associated factors in thai patients with chronic kidney disease and kidney transplant recipients. J Med Assoc Thai 2017; 100:56-69.

11. Yuan C, Wang J, Ying M. Predictive Value of carotid distensibility coefficient for cardiovascular diseases and all-cause mortality: A meta-analysis. PLoS One 2016; 11(4): e0152799. http://doi.org/10.1371/journal.pone.0152799.

12. Alderman $\mathbf{M H}$, Cohen $\mathrm{H}$, Madhavan S. Distribution and determinants of cardiovascular events during 20 years of successful antihypertensivetreatment. J Hypertens 1998; 16(6):761-9. http://doi.org/10.1097/00004872-19981606000007.

13. Franklin SS, Khan SA, Wong ND, Larson MG, Levy D. Is pulse pressure useful in predicting risk for coronary heart Disease? The Framingham heart study. Circulation 1999; 100(4):354-60. http://doi.org/10.1161/01.cir.100.4.354.

14. Mitchell GF, Moyé LA, Braunwald E, Rouleau JL, Bernstein V, Geltman EM, et al. Sphygmomanometrically determined pulse pressure is a powerful independent predictor of recurrent events after myocardial infarction in patients with impaired left ventricular function. SAVE investigators. Survival Ventricular Enlargement Circulation 1997; 96(12):4254-60. http://doi.org/10.1161/01.cir.96.12.4254.

15. Piepoli MF, Hoes AW, Agewall S, Albus C, Brotons C, Catapano AL, et al. 2016 European Guidelines on cardiovascular disease prevention in clinical practice: The sixth joint task force of the european society of cardiology and other societies on cardiovascular disease prevention in clinical practice (constituted by representatives of 10 societies and by invited experts) developed with the special contribution of the European association for cardiovascular prevention \& rehabilitation (EACPR). Eur Heart J 2016; 37(29):2315-81. http://doi.org/10.1093/eurheartj/ehw106.

16. Ha JY, Kim MK, Kang S, Nam JS, Ahn CW, Kim KR, et al.
Serum ferritin levels are associated with arterial stiffness in healthy Korean adults. Vasc Med 2016; 21(4):325-30. http://doi.org/10.1177/1358863x16629728.

17. Lin KC, Tsai MY, Chi CL, Yu LK, Huang LH, Chen CA. Serum ferritin is associated with arterial stiffness in hemodialysis patients: Results of a 3-year follow-up study. Int Urol Nephrol 2015; 47(11):1847-53. http://doi.org/10.1007/ s11255-015-1090-1.

18. Mourad JJ, Pannier B, Blacher J, Rudnichi A, Benetos A, London GM, et al. Creatinine clearance, pulse wave velocity, carotid compliance and essential hypertension. Kidney Int 2001; 59(5):1834-41. http://doi.org/10. 1046/j.15231755.2001.0590051834.x

19. Kharlamova UV, Il'icheva OE. Determinants of vascular wall stiffness in patients with chronic renal disease undergoing hemodialysis. Klin Med 2012; 90(11):44-7.

20. Ben-Shlomo Y, Spears M, Boustred C, May M, Anderson SG, Benjamin EJ, et al. Aortic pulse wave velocity improves cardiovascular event prediction: An individual participant meta-analysis of prospective observational data from 17,635 subjects. J Am Coll Cardiol 2014; 63(7): 636-46. http://doi.org/10.1016/j.jacc.2013.09.063

21. Kanbay M, Afsar B, Gusbeth-Tatomir P, Covic A. Arterial stiffness in dialysis patients: where are we now? Int Urol Nephrol 2010; 42(3):741-52. http://doi.org/10.1007/ s11255-009-9675-1

22. Nakahigashi M, Tsukaguchi $H$, Morimoto S, Nakano C, Ueda $\mathrm{H}$, Someya $\mathrm{K}$, et al. Determinants of the change in arterial stiffness in peritoneal dialysis patients. Int Heart J 2017; 58(6):915-25. http://doi.org/10.1536/ihj.16-624

23. Yang XF, Ding FM, Ye YC, Zhang SY. Relationship between neutrophil-to-lymphocyte ratio and pulse wave velocity in young patients with systemic lupus erythematosus. Chin Med J 2018; 131(1):10-15. http://doi.org/10.4103/ 0366-6999.221272.

24. Yanyan Li, Xiaofang Chen, Lingzhi Huang, Jinyang Lu. Association between neutrophil-lymphocyte ratio and arterial stiffness in patients with acute coronary syndrome. Biosci Rep 2019 ;

39 ( 5 ) : B SR 20190015 . http://doi.org/10.1042/BSR20190015. 